Good to Share? The Pecuniary Implications of Moving to Shared Service Production for Local Government Services

\begin{abstract}
Shared services are often lauded as an efficacious means of reducing municipal expenditure and thereby improving waning financial sustainability. However, most of the extant theoretical and empirical work only considers costs and benefits at the level of the specific service in question and hence fails to capture many of the wider benefits and costs that might accrue to local governments. In this paper we first build a schematic structure to illustrate the benefits and costs of moving from separate to collaborative production at the level of individual local authorities. We then test two hypotheses drawn from the schematic against a five-year panel of expenditure data. We find evidence of increased expenditure in the order of eight per cent that prima facie runs counter to the objectives of many municipal managers engaged with shared services. We conclude by considering the implications of our findings for cooperative ventures between local authorities.
\end{abstract}

Shared services are often lauded as an efficacious means of reducing municipal expenditure and thereby improwing waning financial sustainability. However, there is a dearth of empirical evidence anost of the extant empirical work only considers costs and benefits at the level of the specific service in question and hence fails to capture many of the wider benefits and costs that might accrue to local governmentst the whole-of local-government tevel to validate the claims made by advocates of shared services. Moreover, theorising at the whote of local government levellevel of the local government unit is incomplete and neglects significant costs arising indirectly from cooperative ventures and thus neglects costs that are exogenous to the particular service being shared. In this paper we first build a comprehensive modelschematic structure to illustrate the benefits and costs of moving from separate to collaborative production at the level of individual local authoritiesgovernments of the whole-of local-government implications arising from adoption of shared services, which is applicable to all local government systemsjurisdictions. We then test our model against a five-year panel of expenditure datatwo hypotheses drawn from the schematic structure against a five yearfive year panel of expenditure data. We find evidence of increased expenditure in the order of eight per cent whichcent that prima facie runs counter to the objectives and narratives of many muicipallocal government managersexecutives engaged with shared services. We conclude by considering the implications of our findings for cooperative ventures between local anthorities.

KEYWORDS: Shared services, operational expenditure, transaction costs, exogenous costs

\section{Formatted: Highlight}

Formatted: Highlight

Formatted: Highlight

Formatted: Highlight

Formatted: Highlight

Formatted: Highlight

Formatted: Highlight

Formatted: Highlight

Formatted: Font: Not Italic, Highlight

Formatted: Font: Not Italic

Formatted: Highlight 
Page 2 


\section{Introduction}

Numerous reasons have been tendered for why shared provision of local government goods and services might be preferred over other production arrangements (Chen and Thurmaier 2009; Tomkinson 2007). For instance, it has been argued that shared services may facilitate more coherent regional planning (Kim and Warner 20172016), deliver improvements to service quality (Aldag and Warner 2017), promote innovation (Carr and Hawkins 2013), reduce professional isolation and address recruiting difficulties relating to managerial and technical expertise, especially in rural areas (Dollery et al 2016 Conway et al. 2011; Bel and Warner 2015). In addition, shared services have also been cited as a mechanism for internalising externalities (whereby provision of a service in one local government area might otherwise result in positive or negative side-effects in neighbouring municipalities) (Kwon and Feiock 2010).

However, the most common rationalisation for shared service arrangements rests on the assertion that eo-operative-collaborative ventures will result in reduced expenditure (Dollery et al. 2016; Noda 2017). This motivation has become particularly important given the austerity measures imposed by many national governments in the wake of the Global Financial Crisis (Aldag and Warner 2017). Furthermore, a belated realisation that municipal mergers have proved largely unsuccessful in improving local government financial sustainability has also encouraged policy makers and local authorities alike to consider the use of shared service production (Grant and Drew 2017). Indeed, 'often consolidation and cooperation are seen as alternative tools for confronting similar problems', with opponents of amalgamation stressing that shared services can be an efficacious means of capturing the benefits of scale without the expense and disruption that necessarily accompanies eouncilmunicipality consolidation (Bel and Warner 2015, p. 64).

A substantial empirical literature exists on the impact of municipal mergers on council performance, including operating costs (Allers and Geertsema 2016). Furthermore, recent work has examined the system-wide effects of municipal mergers on costs (Grant and Drew 2017Đrew et al. 2016). In addition, a significant body of empirical work has considered the effects of privatisation in local government (Bel et al., Fageda and Warner 2010). However, much less effort has been directed at investigating the impact of shared services on the costs of service provision (Bel and Warner 2015; Bel and Gradus 2018; Blaeschkea and Haugb 2018). As Bel and Warner (2015, p.53) have observed 'cooperation has received far less attention than privatization, and the literature is still scarce with respect to cost evaluation'.

Indeed, the evidential basis for claims of costs-savings from shared services is both scant and inconclusive (Aldag and Warner 2017; Dollery et al. 2016). Most of the evidence in both the scholarly and grey literatures is survey-based and frequently lacking in rigour (Bel and Warner 2015; Carr and Hawkins 2013). In addition, much of the 'grey literature' is clouded by moral hazard (see, for example, KPMG 2015). Moreover, the bulk of empirical evidence relates to a single class of shared services (waste collection and processing) is restricted to only considering the pecuniary effects at the level of the particular service in question -fgenerally waste collection and processing $(\div$ (Bel and Warner 2015)_- -and hence may

Formatted: Highlight

Formatted: Highlight 
neglect important benefits and costs that only occur at the wider level of individual local eouncilsgovernments. An unfortunate consequence of these various gaps and deficiencies in the empirical literature is that local government policy makers and municipalitie-councils alike make important decisions, often involving high up-front costs, in the absence of soundupportive empirical evidence.

There are a number of reasons for believing that shared services - far from enhancing municipalefficiency may generate higher unit costs, particularly at the whole of locat government level. Some of these factors have been considered in the shared service literature and include inter alia the nett effect of agency costs, information costs, division costs, coordination costs and defection costs (see, for example, Klok et al. 2018; Kwon and Feiock 2010; Carr and Hawkins 2013). However, the literature has hitherto ignored other important reasens for why shared services may exacerbate local government financial sustainability problems. These reasons include the negation of factors which would otherwise underpin economically efficient decentralised government, as well as exogenous costs arising indirectly from the shared service enterprise. In general, these causes of reduced efficiency flowing from shared service adoption have been overlooked due to the foeus in the literature on analysing single classes of local functions and local services rather than whole of locatgovernment outcomes. The extant literature has made note of a number of reasons for why a move from separate to shared service provision may not generate expected pecuniary savings when considered at the level of the specific service collaboratively produced. In particular, co-ordination, division and defection costs have been identified as having the potential to 'completely offset any production cost savings gained through intergovernmental cooperation' (Carr and Hawkins; 2013, p. 229). However, when one moves beyond the level of the service in question to also consider costs that might only be evident at the level of individual local authoritiesgovernments, the potential for shared services to result in nettt pecuniary savings seems even more unlikely. We refer to these costs as 'exogenous costs' because they do not relate directly to the specific service produced collaboratively and would normally lie outside of nettł benefit calculations at the service level, such as the (examples include erosion of economies of scope, failure to meaningfully redeploy assets and staff, and residual functions retained by the local government). By broadening the unit of theoretical and empirical analysis to consider individual local governments (rather than just individual services), we can better account for these exogenous costs and thus In this paper we address anthis important gap in the literature by considering the effects of shared services on the expenditure at the whole of local government level.

The paper is divided into four main partsis divided into four main parts. In the next section, we draw attention to the benefit and cost calculus which emerges when we broaden our perspective from the level of specific services to the level of the local government unit. Im particular, we note the salience of exogenous costs to a local government level evaluation of the nett pecuniary outcomes arising from the shift to shared production. WFollowing this we then outline an empirical strategy to investigate the differing nettt pecuniary outcomes associated with shared services by geographically adjacent municipalities under the assumption that services had previously been produced separately. . In the next section, we

Formatted: Highlight

Formatted: Highlight

Formatted: Highlight

Formatted: Highlight 
develop a comprehensive framework for analysing the whole-of-local-government expenditure effects arising from participation in shared service arrangements. In particular we draw attention to the salience of heterogeneity and number of partner municipalities, transaction costs, and costs exogenous to the co-operative venture. This leads us to develop two hypotheses which we subsequently test through employing a five year panel of empirical data. Following this extension to the extant theory, we outline our empirical strategy and the sources of the data that we use. Thereafter, we consider the results obtained from testing our hypotheses against panel data where we find statistically significant evidence that supports eur theoretical insights regarding the high likelihood that shared service arrangements may result in increased local government expenditurediscuss the statistical associations arising from our econometric analyses on a five--year panel of South Australian (SA) data. We conclude our paper with a consideration of the implications arising from our findings-discussion of the implications of our work for practitioners and scholars alike- along with a suggestions for future brief outline of the work whichwork that might follow-from a new research agenda recalibrated at the level of individual local governments.

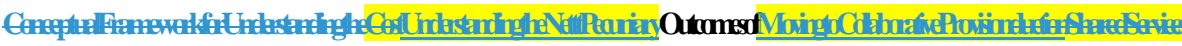

Before moving on to consider specific pecuniary benefits and costs arising from moving service production to a collaborative arrangement it is important to briefly consider the economic rationale for decentralised government. The decentralisation theorem 'establishes, on grounds of economic efficiency, a presumption in favour of decentralised provision of public goods with localised effects', which occurs principally as a result of the capacity to cater to the different preferences and production costs which is unlikely to occur in (more uniform) centralised public service provision (Oates 1999, p. 122). The idea here is that for some public goods residents and business have particular tastes and that by matching the public good offerings to the tastes of the resident consumer we are able to maximise efficiency in a way that might not be possible in more centralised production. For instance, residents in some suburban areas may have a preference for additional green waste collections, but residents in other areas may be content with simplyiust a general waste collection (such asfor example residents living in high densityhigh-density areas dominated by apartments). Moreover, the costs of providing services will vary by location. $-\mathrm{T}$ - thus, even if tastes were similar, the differing costs would likely result in entirely different benefitcost evaluations and hence choices by citizens and the local authoritiesgovernments that represent them (Dollery et al., 2006). When combined with a Tieboutian_(1956) conceptiontian ideas that citizens sort themselves into more or less homogenous groups (homogeneity (in terms of tastes for public goods), then the ability to tailor service provision through decentralised government promises optimal efficiency (Grant and Drew 2017).

When local governments combine to produce services collaboratively there is the potential that efficiency might be reduced if the service in question is one that was previously produced to reflect varying tastes of residents and if the service produced collaboratively is done so at a uniform standard (Feiock- 2007). However, nNot all services are tailored to the
Formatted: Highlight

Formatted: Highlight

Formatted: Highlight

Formatted: Highlight

Formatted: Highlight

Formatted: Font: Italic, Highlight Formatted: Highlight 
tastes of residents since (sometimes standards are regulated by higher tiers of government). Moreover, shared services need not be produced to a uniform standard (although it would often invoke additional costsseem difficult to manage a collaborative enterprise where there were various standards of services in place depending on the location of the resident). However, in the cases where services previously tailored to the taste of local government residents are shifted to a uniform standard produced by a collaborative venture of two or more local governments, then it will be the case that the arrangement will weakenundermine the foundations behind the economic rationalepreference for decentralised government. This suggests that the more heterogeneous (in terms of resident tastes for public goods) the populations comprising theare of local government areass entering into collaborative arrangements, then the greater the potential for changes in economic welfare arising from provision of shared services at a uniform standard. I-(it also follows that loss will be proportional to the number of heterogeneous partners involved (- - Carr and Hawkins; 2013 ).

It is important to stress thatNotably heterogeneity in local-government servicesgoods is not restricted to demand-side forces. - - I-it is also possible that different local governments will exhibit heterogeneity on the supply side. The clearest case of supply-side heterogeneity is in the area of production processes where local governments may choose varying combinationslevels of input factors (labour and capital/labour ratios). Under these circumstances, mMoving to shared services when constituent local governments previously exhibited supply-side heterogeneity will result in some change in production process for at least one local government, with likely consequences for unit cost. This is a benefit or cost directly contingent uponfollowing on from the decision to produce services collaboratively. It is thus and is therefore bestconsideredthought of as anelement of thenettt pecuniary outcome arising from a shift to collaborative production.

Our purpose in this papere work that follows is to make clear how the specific benefits and costs dealt with in the literature devolveresolve into pecuniary outcomes arising from the decision to move from separate production to a collaborative arrangement. It is entirely possible that other benefits might arise from the move to shared services: (for instance, the quality of services might improve thus predicatingsuggesting better value for residents.), However, buthere we are enly-concerned only with questions relating to the expenditure implications for local governments. To achieve this objective we first examine pecuniary benefits associated with moving to shared service production. This is followed by a brief discussion of pecuniary costs. Following this we present a schematic-structure that summarises our arguments and can be used as a helpful tool for decision making by practitioners. We then derive two hypotheses (from a number of questions that might be asked in relation to the schematic-structure), before proceeding to the sequent section on our empirical design and context for the study.

\section{Pecuniary Benefits of Moving to Shared Services}

A major caveat to the decentralisation theorem, which we noted earlierreviewed above, resides in its presumption- that efficiency outcomes might be improved through the capture ofby economies of scale-able to be captured by less decentralised (and hence larger) government units. Economies of scale refer to the proposition that - under certain conditions

Formatted: Font: Italic, Highlight

Formatted: Highlight

Formatted: Font: Italic, Highlight

Formatted: Highlight 


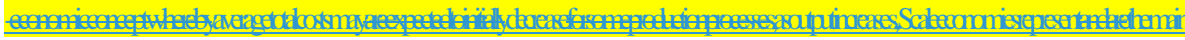
source of pecuniary benefits citednoted in the literature (see, for example, Feiock 2007). Scale eEconomies generally derive from greater specialisation associated withpossible at higher output, use of excess capacity for eapital intensivecapital-intensive plant, and enhanced purchasing power. However, it is important to note that not all local government production functions exhibit economies of scale. Indeed, the empirical evidence for economies of scale to date has been rather mixed. Moreover, and-where evidence of economies has been uncovered it has tended to occur at relatively low levels of output (Fahey et al.- 2016). It is also important to understand that once output has been increased to a level that fully exhausts economies of scale, then this is typically followed by a relatively longarge domain of constant returns to scale (where costs do not change as output increases). If output is expandsed even further, then diseconomies of scale may emerge (and hence increase average total cost accompanying greater output) as a result of problems inter alia coordinating large numbers of staff and a reduction in the transparency of the organisation. Figure 1 depicts potential economies related to scale that may emerge for some local government functions. For these types of functions moving to a shared service arrangement may substantially reduce unit cost if output by separate production had not fully exhausted economies of scale and, if the combined output of the collaborative arrangement is such that it does notn't incur significant diseconomies of scale.

\section{[PLEASE INSERT FIGURE 1 HERE]}

\section{Figure 1: Average Total Costs for Production Functions Exhibiting Economies of Scale}

A second source of potential pecuniary benefits arising from a move to shared services occurs when the arrangement results in externalities being internalised (LeRoux et al. 2010). Externalities occur when the conduct of one party has positive or negative effects on another party. For example, flood mitigation works by a local government may have significant implications for adjoining municipalities. By entering into shared service arrangements with geographically adjoining local councilsgovernments it may be possible to more effectively share the costs or benefits of negative or positive externalities. For instance, if flood mitigation work at a given municipality has reduced the likelihood of flooding for neighbouring municipalities upstream, then it might be possible to have these neighbours internalise some of the costs for the benefits that they have received through entering into collaborative arrangements (and co-ordinated efforts might also improve non-pecuniary outcomes). Having neighbours internalise benefits or costs as a result of collaboration not only provides a pecuniary advantage to the municipality which previously bore the entire cost, but may also-may lead to more effective and economically efficient collaborative solutions. F(for example, it might be cheaper in the long run for the upstream municipality to also do some work to avoid the build-up of debris and invasive weeds that would otherwise continue to inflict costs oneause work for the downstream local authoritygovernment).

The third source of potential pecuniary benefitsoutcomes arise from medium-run dynamic improvements as a resultattendant on-of collaboration. For instance, Conceivably the act of collaboration may result in municipalloeal government staff learning new skills and better
Formatted: Font: Italic, Highlight

Formatted: Highlight

Formatted: Font: Italic, Highlight

Formatted: Highlight

Formatted: Font: Italic, Highlight

Formatted: Highlight

Formatted: Highlight

Formatted: Highlight 
ways of producing services (Brown and Potoski- 2005). It may also be the case that larger collaborative ventures serve toean attract more skilled staffstaff who are more skilled. In addition, , these ventures mayand provide greater opportunities for professional staff to betterpeer review and otherwise share professional knowledge. This area has largely escaped attention in the shared services literature. MoreoverHowever, it and would be difficult to measure and test empirically, largely because (because-cost reductions attendant on learning typicallywould emerge over the medium term and occur unevenlyt.

It should be stressed thatNotably all of these benefits from collaborative production could be gained through other meansmechanisms. For instance, scale can be increase through boundary change and consolidation, - although changes of this type necessarily result in all functions being increased to the same scale, which can be problematic given empirical the evidence onf functionally specific optimal scale. In similar vein, externalities can be addressed through transfer payments and learning through staff exchange or professional networks. However, it is certainly the case that shared services offers more flexibility than its alternatives:- in principle, local eouncilsgovernments, could mix and match partners for different functions in order to optimise scale and source complementary skills or plant. Flexibility is thuserefore an important attribute of the shared service model that may give rise to greater pecuniary benefits than might be achieved through other avenues.

\section{Pecuniary Costs of Moving to Shared Services}

Entering into a shared service arrangement necessarily involves new upfront costs. U(tupfrontcosts also occur for separate service production-alse and may even be lower in this latter case.- However,but in this paper we look at shared services from established functions and thus are only concerned with the decision to move from separate to shared productionduction). In an economic sensesense, all upfront costs are-considered to be fixed costs sincebecause they arise prior to before any service productionn occurs (and would exist even if there were nonil production; ) (Brown and Potoski 2005). However, it is certainly the case that upfront costs will vary inter alia according inter aliat to the number of partner municipalities, supply-side heterogeneity of partner municipalitiestoeal governments, and the type of sharedthe service to be shared. The literature includes the costs of finding partner municipalities, holding negotiations, establishing or renegotiating contracts with suppliers, and consulting with affected staff and local residents (see, for instance, Carr and Hawkins 2013).

However, tThere are also a number of significantizeable and unanticipated costs thatseem to have largely escaped notice in the literature. For instance, contributions of assets may involve recognition of losses on disposal where the book value differs from the fair value of the asset contributed. Most of these costs will be recognised in accounting statements produced at the end of the financial year in which the shared service arrangement is established. However, from an economic perspective it is probably more appropriate to think of these costs as being apportioned over the life of the collaborative venture, falthough we recognise that this will often be difficult to factor into the decision--making process where the life of the arrangement

Formatted: Highlight

Formatted: Font: Italic, Highlight

Formatted: Highlight

Formatted: Font: Italic, Highlight

Formatted: Highlight 
is not known a priori). Thus, under this conception, the value derived from the upfront costs is proportional to the duration of the life of the shared service arrangement.

Transaction costs arise due to uncertainty, information asymmetries and the potential for partners to behave in an opportunistic manner (Brown and Potoski; 2005). They-and include inter alia division, information, co-ordination, free-rider and defection costs. Division costs refer to how the gross transaction surplus is distributed between participatingeonstituent local authoritiesgovernments. There is good reason to believe that larger local autherities or municipalitiesies contributing greater expertise may use their relative power and knowledge to obtain a larger slice of the gross transaction surplus than might otherwise be warranted (Carr and Hawkins 2013). In addition, the cost structure for each constituent municipality may well be dissimilar as a result of both supply-side and demand--side heterogeneity. This implies that even if the gross accounting surplus was distributed in proportion to the number of units previously produced, the resultant bargaining surplus might be asymmetrically apportioneddistributed between participating municipalities. In contrast, information costs, on the other hand, apply to both local government entities and the shared service venture (where the former is an element of agency costs) and relate to the need to provide information for statutory reporting and to meet the expectations of constituent local authorities. Information costs and thus represents an ongoing cost for most shared service arrangements.

Co-ordination costs are also an important component to consider for the calculation of nett shared services nett savings. Co-ordination costs-and refer principally to the staff time employed to ensure that all parties to the cooperative venture maintain common goals finitially established and reflected as upfront costs in the negotiating phase -t and act in a fashion that reflects the these goals. Co-ordination costs are likely to be proportional to the number of municipal partners. They and may be mitigated by trust relationships promoted by informal networks, professional standards, and the likelihood of repeated 'games', although if partners ultimately prove untrustworthy then savings in this area are likely to be eliminated or exceeded elsewhere (LeRoux et al. 2010; Feiock 2007). One way in which savings in co-ordination costs arising from misplaced trust may be eroded or eliminated is in the area of free-rider costs. Free-riding occurs in cooperative local service partnerships when an entity attempts to pay less than the full price for a good or service consumed (Carr and Hawkins 2013). Free-riding might occur if any of the parties to the shared service arrangement seek to delay contributions (such as i.e.staff, assets or funds) or contribute less than agreed a prioriwhat might have been agreed. This may not always be-a visible. For example, a local authority could seek to contribute staff or assets of a lower quality than might have been reasonably expected in an effort to transfer a portion of its entity-level liabilities to the shared service partners.

Defection costs are generally given to refer to the costs incurred when a partner entity withdraws from a shared service arrangement (Dollery et al. 2016). A withdrawal of this kind will affect the amortisation of upfront costs, it mayean modify the unit costs of production, it may require the replacement of staff and assets (if repatriated to the withdrawing municipality), and it may require the re-negotiation of contracts. However, the threat of
Formatted: Font: Italic, Highlight

Formatted: Highlight

Formatted: Font: Italic, Highlight

Formatted: Highlight

Formatted: Highlight

Formatted: Font: Italic, Highlight

Formatted: Highlight 
defection - whether actually made by a local municipality or merely anticipated by other partner municipalities - can also fundamentally upset the bargaining equilibria upon which the shared service arrangement rests and thus result in costs being incurred. For instance, if partner entities believe that one local eouncilgovernment might withdraw, then itthey may be willing to re-distribute the gross transaction surplus or be particularly accommodating to the potential defector's wishes at the expense of the other parties to the collaborative venture.

Agency costs are a cousin of transaction costs and relate to goal incongruence. F- for instance, they arise where an agent does not faithfully represent the interests of the principal, due to an inability to correctly perceive the principal's wishes or a lack of concern for the principal's goals (Brown and Potoski; 2005). In local shared service arrangements, agency costs may be amplified due to both the distance between the principal and agent, as well as the number of agent-principal relationships, given that representatives on a shared service committee or board act as agents of both the constituent municipalities involved as well as local residents (Kwon and Feiock 2010).

This study contributes to the literature on shared servicesdiffers to most in the extant literature because we consider the pecuniary outcomes of shared services at the level of the individual local government rather than the local service in question. As a resultBecause of the different lens through which we view shared services, many costs that reside outside of the specific service being shared become visible. We - and we refer to these expenses as 'exogenous costs' because they are not directly related to the service being shared and would generally fall outside of decision making and empirical analyses conducted at the service level. Major exogenous costs include erosion of economies of scope, additional staff and resource burdens on municipalities as a result of reticence to meaningfully redeploy, as well asnd the need to continue to conduct residual elements of functions that have been shared (such as handling of complaints).

Economies of scope arise when a single organisation produces two or more services whichservices that employ the same factor inputs. For example, the municipal building, information technology and staff used for customer service are typicallyprobably also used for procurement activities. If one function is removed from the direct control of a local authority (and given over to a shared service arrangement), then an erosion of economies of scope may follow. This will result in a relative increase to the unit costs of many of the other services that remain at the local municipality in question, and will effectively be reflected as a nettt cost at the level of the local government unit (and thus occur independently to savings made at the level of the service shared). It is also critical for staff and assets that were previously employed in the function being shared to be meaningfully redeployed if they are not part of contribution to the collaborative arrangement. It is likely that many local municipalities will be reticent to dismiss staff (and legislation or unionisation may in any event prevent this in any case) and sale of assets may result in the realisation of book losses. The third major class of exogenous cost result from residualisation of elements of the function transferred to shared services. In particular, because 'citizens have difficulties in accurately identifying the providers of the services they receive' it is likely that local governments will still have to field complaints and inquiries about services long after the 
function has been transferred to the collaborative venture (Brown and Potoski 2005, p. 330).

BNotably, because exogenous costs relate to management decisions and the characteristics of particular local governments (such as use of the same factors for production of multiple services), exogenous costs may manifest differently for different municipalities even where the same service is shared.

It is worth stressing that Notably most of the pecuniary costs that we have discussed arise entirely as a resulta result of the decision to enter into a shared service arrangement. The main exceptions to this are information, co-ordination, agency and free-rider expenses that probably also occur for separate production (but manifest in different ways and are easier to manage in-house (-Brown and Potoski 2005)).

Table 1 summarises the pecuniary benefits and costs arising from the decision to move from separate production to shared service production.

\section{[PLEASE INSERT TABLE 1 HERE]}

Table 1. Pecuniary Benefits and Costs of Moving From Separate to Shared Service Production

\section{A Schematic-Structure to Inform Decision Making}

In order to understand why shared services, at the local government level, might result in reduced efficiency it is helpful to remind ourselves of the economic rationale for decentralised government. The decentralisation theorem 'establishes, on grounds of economic efficiency, a presumption in favour of decentralised provision of public goods with localised effects', which occurs principally as a result of the capacity to cater to the different preferences and production costs which is unlikely to occur in (more uniform) centralised public service provision (Oates 1999, p. 122). By contrast, shared service provision at a regional scale may necessitate uniform standards thereby negating the inclusion of localised t that couldmight be expected to assist decision makers who are considering moving from separate to shared production of a given servicealgorithm. Here $\alpha_{1}$ refers to the number of shared service $\beta_{1}$ refers to the heterogeneity of said partners. These two factors interact to produce a weighting applied to upfront costs and transaction costsongoing costs where expenses might be expected to rise as the number and heterogeneity of partners increases. Both upfront and ongoing costs are likely to be affected by these two factors although, as we have noted, some costs (like for example coordination costs) will be more sensitive to this weighting than others. $-\gamma_{1}$ refers to the duration of thesharedservicearrangementanditisrequiredtoapportionupfironteostsoverthelifeof the ventureensurethatdecisionmakersiemain cognisant that in an economic sense upfront costs (which may be substantial) should be apportioned over the expected life of the venture (although we acknowledge that this may not always be clear). It is noteworthy that the exogenous costs appear outside of the parentheses whichparentheses that reflects the fact that they are not dependent on either the number of partners, or the heterogeneity of partners.

Formatted: Font: Bold

Formatted: Font: Bold

Formatted: Font: Italic, Highlight

Formatted: Highlight

Formatted: Font: Italic, Highlight

Formatted: Highlight 


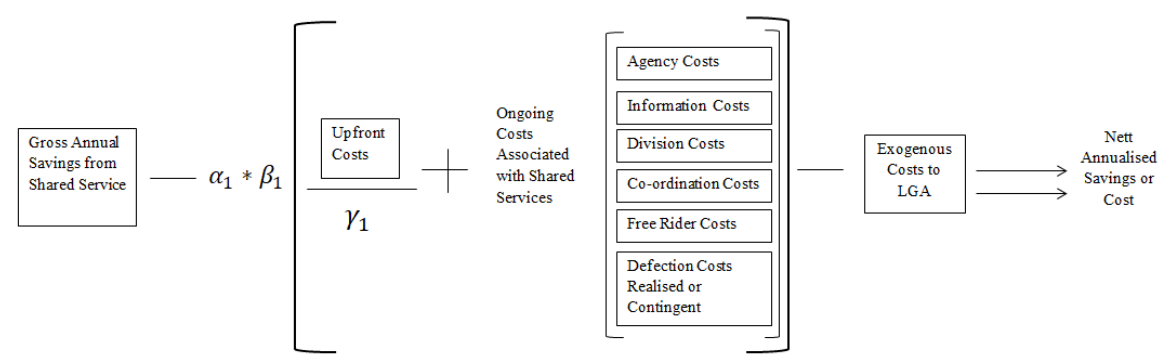

This shared service savings-nettt pecuniary algorithm points to the first hypothesis that we will test in the empirical work which follows:schematic-structure is also useful to scholars because it makes the calculus explicit for the case where services previously produced separately are moved to collaborative production. Moreover, itthe schematic clearly identifies the different costs which only become apparent when a local government level analysis is done. Indeed, given the preponderance of costs and the relative uncertainty of some benefits occurring (such asfor instance economies of scale), it would seem likely that a move from separate to shared production may well result in an increase to unit expenditure when considered in terms of mean aggregate response. A number of hypotheses come to mind when examining the schematic-structure, but we have selected just two to test in this instance owing to word length cthe eonstraints inherent in a single journal article and data limitations (such as for example data on upfront costs or resident tastes):

H1: due to a combination of upfront costs, transaction costs and exogenous costs, tThe use of shared services, rather than continuing to supply services separately, will result in higher levels of expenditure __, on average __, at the whole of loeal government level than ne shared serviceslevel of the local government unit.

In addition, by using disaggregated data relating to the specific shared service employed by particular local councils, we are also able to test a second hypothesis derived from our

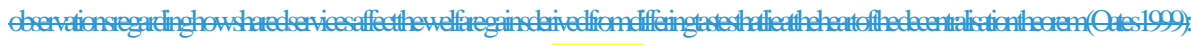
expenditure as a consequence of providing thesesaid services through-co-operative shared service ventures (that may result in uniform standards being imposed).

We now briefly outline our data seurces and empirical methodology which we employ to test eur extensions to the extant theory.
Formatted: Highlight

Formatted: Highlight

Formatted: Highlight

Formatted: Highlight

Formatted: Highligh

Formatted: Highlight 


\section{ContextInstitutional Background and Empirical Strategy}

We tested ourt two hypotheses, and hence some of our theoretical insights, against a five yearfive-year panel of data obtained from the-SA was conducted for the purposes of explication on our nett shared services pecuniary algorithm. The algerithm is applicable to any jurisdiction abread, as is the empirical methodology that we outline (subject to data availability). Indeed, it would be ideal for our study to be replicated in other jurisdictions, given that analyses of multiple jurisdictions is well outside of the constraints of a single journal paper.

SA Auth Australian local government currently comprises 68 local authorities operating under the Local Government Act 1999 (SA) and the Local Government (Elections) Act 1999 (SA) In common with other Australian local government systems, SA councils and are funded by a combination of property taxes ( 71 per cent), intergovernmental grants (14 per cent), user charges (11 per cent) and other revenue (3 per cent) (South Australian Local Government Grants Commission ( $\mathrm{SALGGC}_{2}+2017$ ). In the 2015/16 financial year, property rates generated $\$ 1.55$ billion. Combined with other own source funding (largely user charges), about 86 per cent of total local government income may be characterised as 'own-source' revenue (South Australian Loeal Government Association (SALGASA) 2017).

Just over a third of SAøuth Australia councilmunicipalities conduct at least one eo-operative collaborative venture, although the precise number varies slightly from year to year in response to new arrangements being established and existing arrangements discontinued or altered. It should be stressed that -the degree of variation is not sufficient to test dynamic effects such as benefits from learningt. Table $1-2$ categorises shared service arrangements according to eight different types of functions. The most common type of shared service is waste management and the least common is cemetery services. All services shared are part of a historically long remit, thus making it reasonable to assume that services now shared were previously provided separately. Moreover, all shared service arrangements that currently take place in SA do so between geographically adjacent municipalities. TThe great majority of municipalities involved in eo-operativecollaborative ventures share just one service $(-$-with only three councilmunicipalitiess providing more than two cooperative services). In the present context, this suggests a low probability of interaction effects, which would have been difficult to model given both the small numbers of councilmunicipalities with multiple co-operativecollaborative ventures and the permutations in operation.

\section{[PLEASE INSERT TABLE $1 \underline{2}$ HERE]}

To determine if shared service arrangements have a statistically significant significantly positive association with operational expenditure at the whole of loeal government levellevel of individual local government units, a conventional ordinary least squares model-with time fixed effects ${ }^{+}$was employed. Fixed-effects was not suitable given that the regressors of interest were time invariant or almost time invariant-(Kennedy 2003) and random-effects could not be employed because the Hausman test was unfavourable, thus suggesting that the
Formatted: Highlight

Formatted: Highlight

Formatted: Highlight

Formatted: Highlight

Formatted: Highlight

Formatted: Highlight

Formatted: Highlight
Formatted: Highlight

Formatted: Highlight 
explanatory variables might be correlated with the random error term $(\mathrm{p}=0.0000)$. The final model specification was:

Where $\mathbf{E}$ is the operational expenditure of a local government (less depreciation expenses), expressed on a per assessment basis, $\mathbf{X}$ is a vector of control variables which are expected to influence operational expenditure (the full list is provided below), $\mathbf{S}$ is a binary variable coded 1 if the municipality operates under a shared service arrangement (note that this coding will also be applied in subsequent models disaggregating shared services into individual service categories), and 0 otherwise (if no shared service arrangement exists for the municipality), and $\mu$ is an independent and identically distributed error term. To account for differences in eouncilmunicipality performance over the period under analysis, indicator variables representing individual years were applied.

The control variables selected for the model $(\mathbf{X})$ which are theorised to significantly influence local government expenditure levels include the total number of rateable assessments (including residential and commercial properties), population density, the proportion of residents under 15 and aged residents (measured through the proportion of residents receiving an aged pension), the proportion of indigenous residents (those identifying as being of an Aboriginal or Torres Strait Islander (ATSI) background), the proportion of residents from a non-English speaking (NESB) background, the socioeconomic status of residents (measured through the median employment income received and the percentage of residents receiving unemployment (Newstart) payments), the proportion of residents receiving federal assistance (those receiving the disability support pensions (DSP)), the location of the councilmunicipality (whether it is an urban or rural councilmunicipality), the length of sealed and unsealed roads, and the Commonwealth Financial Assistance Grant (FAG) received by local authorities. The value of total assessments (and its quadratic term used in supplementary models) were selected to account for the potential presence of economies of scale (or diseconomies of scale) in local government service provision (see Kwon and Feiock 2010) which, if present, may serve to lower (increase) expenditure levels incurred by a municipality. It is noteworthy that - because the service remit of Australian local government is orientated principally towards services to property - we have used number of rating assessments (i.e. number of rateable properties) as our unit of analysis (Drew and Dollery 2014). A measure of population density was included in the model to account for potential economies of density (a situation whereby average costs decrease as the population density for an area increases (Grant and Drew 2017Holeombe and Williams 2008)). Measures of population demographics and socio-economic status were included to account for the welldocumented effect which socio-economic disadvantagedeprivation has in reducing or increasing resident demand for services or service quality (Andrews 2004).

The location of a eouncilmunicipality (i.e. whether it operates in a rural environment or an urban environment) was controlled for in response to the empirical prevalentevidence of differing provision of services and hence unit costs of providing services incurred by rural and urban local government respectively ${ }^{2}$ (with the former used as the reference category). 
More specifically, residents (and businesses) in rural areas generally receive a lower quantity and quality of services compared to their urban counterparts. The conditions of local roads maintained by a local authority (whether they are sealed or unsealed) were included to account for the substantial differences in expenditure (per kilometre) required to maintain these assets (sinceas maintenance costs for the former type of road typically exceed the latter). Finally, the inclusion of data relating to FAGsfinancial assistance grants is justified due to the previously observed impacts on raising municipal spending (known as the 'flypaper effect'), potentially serving to increase municipal expenditure compared to an equivalent source of self-generated income (Dollery and Worthingten 1995et al. 2006). To ensure the robustness of the results obtained, supplementary models incorporating alternative specifications (and an alternative mixed-effects statistical approach) were examined and found to produce similar results (t. T (these results can be obtained from the authors) upon request).

Where necessary, variables have been transformed into logarithms to correct for skewed distributions (see Table $2 \underline{3}$ ) contains the individual variables transformed). Summary statistics for the variables employed in this analysis are presented in Table 2.

\section{[PLEASE INSERT TABLE 32 HERE]}

Data has been sourced from the Australian Bureau of Statistics (ABS) National Regional Profile (ABS 2017), the SA Aouth Australian Local Government Grants Commission (LGGC) (20157) Annual Report-(SALGGC 2015), and the audited financial statements produced by SA municipalities. In particular, information used to determine if a municipality operated under a shared service arrangement, and the type of shared service arrangement (if any) was obtained from Note 19 to the financial statements ('Joint Ventures and Interests of Other Entities'), $;$ although for individual counci lmunicipalities this note number occasionally varied), supplemented through appendices to the annual reports, which contain the annual

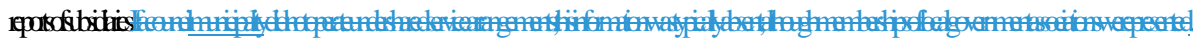


Our regression models are designed to test whether there is a statistically significant association between unit cost and whether or not local government services are produced collaboratively. Moreover, contextual factors mean that our hypotheses are tested for a quite specific scenario: - services which had at some time been produced separately, but are now produced collaboratively in geographically adjoining municipalities. It is important to remain cognisant that in this paper we are not testing many of the broader questions that might derivebe formulated from our schematic-structure. For instance, we are not testing questions of value for money (hence the absence of variables for quality), nor do we seek to investigate in detail the reasons for the change in unit costs (hence absence of variables for production process). We are simply trying to establish whether the decision to move to shared service production has pecuniary implications at the level of individual local governments and hence address an important targe gap in the literature, therebyus establishing a foundation for a future research agenda.

Many municipal goods and-services are not amenable to economies based on scale and even when unit prices are responsive to scale it would be easy for local government to exceed optimal scale (and hence potentially incur diseconomies of seale), especially in the absence of rebust empirical analysis to guide decision making. If we add to this the potential for apportioned upfront costs, transaction costs and exogenous costs to exceed any savings that might arise from expanded output, then it becomes clear that there are strong grounds for hypothesising that shared services might contrary to widespread belief actually increase whole of local government costs.

\section{[PLEASE INSERT TABLE $\underline{4} 3$ HERE]}

THowever, the regressor of interest with respect to $\mathrm{H} 1$ is the dummy variable which indicates whether or not a given local authority is one of the over a third of municipalities that participated in shared service arrangements in SA Aeuth Australia. Model 1 suggests that _on average - local eouncilsgovernments participating in shared service arrangements are associated with an increase to unit cost in the order of $7.79 \%{ }_{2}$ ceteris paribus. This association is statistically significant at the $1 \%$ level and the size of the coefficient represents quite a comparatively strong response (since the average unit costs across $\underline{S A}$ local governmentthe state, over the period of analysis was $\$ 1,589.65)$. The result is important because it broadens the evidential base by considering the pecuniary effects at the level of individual local governments - therebylikely capturing costs previously outside of service level analyses - and in so doing provides scholars and practitioners alike with good reason to pause and reconsider widely held assumptions on the matter (Bel and Warner 2015).

Moreover, this result which strongly supports $\mathrm{H} 1$ is likely to come as something as a surprise to many of the local council managers who have justified participation in co-operative enterprises on the basis of cost-savings. As we have noted there are many other reasons for participating in shared services. However, costs savings is a common motivation. Moreover, prior to the empirical analysis in this paper, there has been a dearth of conceptual inquiry and 


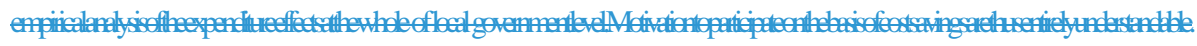
and found that our regressor of interest was consistently significant at or near the reported level. For instance, Model 2 adds a quadratic term for the size proxy (which is frequently done in expenditure function analysis) and the regressors attenuate only slightly (the participation in shared service arrangements is now associated with an $8.11 \%$ increase to unit expenditure). The robustness of our results in the face of alternative specifications is entirely consistent with our theoretical framework which presents a convincing case against the likelihøod of whole of local government pecuniary savings arising from shared service ventures-schematic-structure that highlights the importance of carefully choosing both the service (for example, one amenable to scale economies) and partner municipalities (particularly with respect to homogeneity) most likely to maximise benefits and minimise costs associated with moving to shared service production.

IAs we have noted, in Australian local government- shared services can be classified according to eight different types of serviceses. Moreover, as we have noted, there are solid grounds for presuming that some service types will be more amenable to eliciting lower unit costs than others. Specifically, a large source of welfare gains (and associated costs savings) deriving from decentralised government relate to catering to the differing tastes and preferences of identifiable communities. It would thus seem reasonable to posit that services largely defined by community taste might be most likely to be associated with positive coefficients whilst services that are more likely to beinvariably initially uniform in standard mayight be better suited to eo operativecollaborative ventures(see, for instance, Oates 201319992011 ; Dollery etal. 2006; Grant and Drew 2017).

However, it is no easy matter to definitively determine which services are most likely to vary significantly with community taste in the absence of comprehensive service specific quality data (which does not exist in SA local governmentfor South Australia, nor for most other local government systems). However, it is not unreasonable to suggest that waste collection (some municipalities collect only general waste, others have separate collections for green waste, and various degrees of disaggregation of waste recycling), transport (the frequency and routes of community bus services would seem to be highly responsive to community taste), and procurement (materials ordered will be reflected in most services delivered to residents, ranging from the quality of the paper on which councilmunicipality newsletters are printed through to the quality of materials used to construct substrates and road services) will all be responsive to community taste. By contrast, a minimum level of water quality is imposed on local authorities by statute, whilst the depth and width of graves is regulated by Australian standards and thus cannot change significantly inis thus relatively less likely to be responsivee to community taste (headstones and other monuments are generally purchased separately). We concede that there may be some variation in response to community taste for these services, but the existence of a statutory floor for standards certainly reduces the likelihood of large disparities relative to unregulated services. Similarly health inspections of food retailers and the like, which form the bulk of municipal health shared services, have to be completed according to statutory standards and they are thus unlikely to be overly responsive to community taste (indeed requiring higher standards than legislated might well 


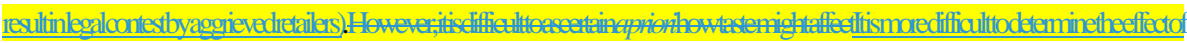
resident taste for other services such as flood mitigation work (in the absence of additional qualitative data) given that flood mitigation works as there are substantial environmental factors toconsider which might reasonably be expected to impact on the frequency and types of works undertaken. Similarly, preferences for equipment are difficult to foretell given that the taste of municipal employees may well override preferences of the local community (who in all likelihood will anyway be oblivious to the brand of telephone or machinery used by councilmunicipality employees).

In sum, if our hypothesising in section 2 is correct, thenwith reference to the theoretical considerationseconomic theory presented in Section 2 and drawing plausible deductions from the nature of some functions in Australian local government, we might reasonably expect positive coefficients for waste, transport and procurement, but negative coefficients for water, health and cemeteries.

Table 43 reports the results obtained under Model 3: Shared waste, transport and procurement services are associated with positive coefficients, although only procurement is statistically significant (where the base group is councilmunicipalities with no shared services). Indeed, participation in shared service procurement was associated with an additional operational expenditure of $18.97 \%$ at the $1 \%$ level of statistical significance relative to the base group of eouncilmunicipalities with no shared service arrangements at all, ceteris paribus. By way of contrast, shared water, health and cemeteries (i.e. shared services which are less likely to reflect local preferences and hence are more likely to generate overall savings) had negative coefficients (with respect to a base group of eouncilmunicipalities with no shared services). However, only one of these shared services had a statistically significant association: health was associated with a $21.71 \%$ reduction in overall unit cost compared to the base group with no shared services whatsoever ${ }_{2}$ ceteris paribus. Of the remaining shared service types, flood works was associated with a-statistically significant positive association of $8.64 \%$ at the $5 \%$ level of significance relative to the base group of no shared services, while shared services for equipment had a negative coefficient, but was not statistically significant.

On balance our evidence provides some support for $\mathrm{H} 2$, but it cannot be considered conclusive. To provide additional support for this hypothesis it would be necessary to conduct analyses for other local government systems, preferably where quantitative investigation and deductive reasoning could be augmented with service quality data, shedding light on thethus shedding more light on the effect of degree of variability reflective of local preferences for given shared services. 


\section{Conclusion and Recommendations}

This paper pursuedset out two related objectives. First we wished to broaden the perspective taken on shared services from the level of the specific service to be shared to the level of the individual local government. The main output arising from this objective was a schematic structure that laid bare the benefit and cost calculus - at the level of an individual local councilgovernment - that emerges when a decision is made to shift from separate to shared provision of services. The second objective; was to empirically investigate the nettt pecuniary outcomes - at the level of individual local authoritiesgovernments - associated with shared services by geographically adjacent municipalities under the assumption that services had previously been produced separately. The main output arising from this objective were a number of econometric analyses conducted on a five yearfive-year panel of SAouth Australian local government expenditure data.

The schematic-structure developed in this paper-work could be a helpful decision-making tool for practitioners considering a shift from separate to shared service production. In particular, ourthe schematic-structure serves a useful purpose by drawing attention to the type of service and service partners most likely to yield optimal pecuniary outcomes. It also provides decision-makers with a thorough account of costs likely to be incurred. -I-in particular, itthe shematic makes explicit exogenous costs which have hitherto been neglected in the literature due to the fact that they only become visible when the unit of analysis is broadened to that of the whole local government entity. Being aware of these costs may help practitioners to optimise outcomes. -Ffor instance, it might prompts decision makers to meaningfully redeploy or retire staff and assets previously engaged in the function that have not been contributed to the collaborative venture.

Our empirical resultsThe empirieal work challenges the findingsresults of many previous service level analyses and thus helps to establish a case for local government level analysis whichanalysis that may better capture all of the costs associated with the decision to shift from separate to shared production. Indeed, it provides evidence of statistically significant and fairlyquite strong mean increases to unit expenditure in the order of $8.11 \%$, ceteris paribus. This suggests that a shift to shared services will typically result in higher expenditure, although readers should remain cognisant that regression looks at the mean response and that some arrangements might in fact result in pecuniary savings (especially if managed carefully along the lines suggested by our schematic-strueture). Indeed, we also provide some evidence, augmented by deductive reasoning, to support the contention that services which are more likely to vary by resident taste are also more likely to experience increases to unit cost in the event that they are shifted to shared production, falthough this cannot be considered definitivet. In sum, our empirical analyses should give practitioners and scholars good reason to pause and rethink some of the pervasive assumptions regarding the pecuniary implications arising from shared service production that are commonly encountered in the grey and scholarly literatures. We emphasise that the empirical work did not test the entire schematic-structure but rather specific questions relating to the aggregate mean response in expenditure associated with shifting services from separate to shared production.
Formatted: Highlight

Formatted: Highlight

Formatted: Font: Italic, Highlight

Formatted: Highlight 
Indeed, our work still leaves a number of questions unanswered and thus sets out an impertant potential future research agenda. For instance, our empirical analysis did not seek to answer questions regarding the mechanism through which the additional pecuniary outcomes came to pass. Future work that can access precise data for upfront, ongoing and exogenous costs respectively would contribute greatly to our understanding of local government level outcomes. The existing analysis is also unable to answer questions about value for money.- Aadditional data, where available, on service quality would be required to investigate this questionissue further. Nor could we investigate dynamic outcomes - in particular outcomes from learning which might arise only in the medium term - due to the fact that the SAouth Australian shared service cohort experienced little change in composition over the five years. In addition, our work cannot be directly applied to the case where collaborative production is contemplated for entirely new services - in these instances, the comparative calculus changes significantly (for instance upfront costs would be required by both separate and shared service production modes, thus significantly increasing the attractiveness of the collaborative option). In sum, whilst the paper has mounted a largely successful challenge to the extant practice of analysing the efficacy of collaborative arrangements at the level of the specific service, it has only begun to exploit the full potential of recalibrating the unit of analysis to the level of individual local governments.

It might also be noted that the theorising and empirical work in this paper is only relevant where the principal motivation for entering into collaborative arrangements is to save money. This is indeed the most commonly cited motivation, but as we outlined in the introduction it is far from being the only reason for sharing production. However, where the motivation is principally pecuniary in nature, then our findingswork makes a strong case that (when viewed from the perspective of nett outcomes for individual local councilsgovernments) it may be prudent to set aside the assumption that it is always good to share.

As we have seen, whereas the empirical analysis of shared services in local government has attracted much less attention than other approaches to improving municipal service provision, such as council consolidation and privatisation, the bulk of empirical work on shared-services has concentrated on the assessment of specific types of service provision, most notably waste eollection and precessing (Bel and Gradus 2018). Furthermore, the conceptual perspectives on shared services in local government have largely been shaped with an implicit emphasis en the impact of a given service and its potential for coeperative provision.

The whole-of-local-government level approach developed in this paper serves to act as a eautionary mechanism in loeal government decision making. It demonstrates inter alia that whether or not a given municipality should enter into shared service arrangements depends to a large degree on (a) the rationale for the cooperative venture and (b) the unit level at which the shared service arrangement is evaluated. Our findings suggest that when pecuniary savings are the major reasen for the proposed venture and when the venture is considered at a whole-of-government level, then it is likely that many potential shared service arrangements should not be implemented.

\section{References}


Aldag, A., \& Warner, M. (2017). Cooperation, Not Cost Savings: Explaining the Duration of Shared Service Agreements. Local Government Studies, doi:

$10.1080 / 03003930.2017 .1411810$

Allers, M. A., \& Geertsema, J. B. (2016). The Eeffects of Llocal Grovernment

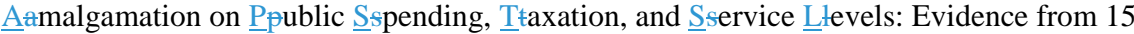

Yyears of Mmunicipal Ceonsolidation. Journal of Regional Science, 56, (4), 659-682.

Formatted: Font: Italic

Andrews, R. (2004). Analysing Deprivation and Local Authority Performance: The

Implications for CPA. Public Money \& Management, $24_{2}(1)_{2} \div 19-26$.

Formatted: Font: Italic

Australian Bureau of Statistics (ABS). (2017) National Regional Profile (2011-2016).

Canberra: ABS.

Bel, G., Fageda, X., \& Warner, M. (2010). Is Private Production of Public Services Cheaper than Public Production? A Meta-Regression Analysis of Solid Waste and Water Services.

Journal of Policy Analysis and Management, 29, (-3), 553-77.

Formatted: Font: Italic

Bel, G., \& Gradus, R. (2018). Privatisation, Ccontracting out and Iinter municipal

Ecooperation: Nnew Ddevelopments in Elocal Ppublic Sservice Ddelivery. Locat

Government Studies, 44, (1), 11-21.

Blaeschke, F., \& Haug, P. (2018). Does Iintermunicipal Ccooperation Iincrease Eefficiency?

A Ccenditional Mmetafrentier Aapproach for the Hessian Wwastewater Ssector. Locat

Government Studies, 44,(1), 151171.

Formatted: Font: Italic

Carr, J., \& Hawkins, C. (2013). The Costs of Cooperation: What the Research Tells Us About Managing the Risks of Service Collaborations in the U.S. State and Government Review, 45 ,

Formatted: Font: Italic (4), 224-239. 
Chen, Y., e-Che \& Thurmaier, K. (2009). Interlocal Agreements as Collaborations: An Empirical Investigation of Impetuses, Norms, and Success. American Review of Public Administration, $39,(5), 536-52$.

Conway, M., Dollery, B.E., \& Grant, B. (2011). Shared Service Models in Australian Loeat Government: The Fragmentation of the New England Strategic Alliance 5 Years On. Australian Geographer, $42,(2), 207223$.

Dollery, B. E., Kortt, M. A., \& Drew, J. (2016). Fostering Shared Services in Local

Government: A Common Service Model. Australasian Journal of Regional Science $e_{2} \cdot 22,(2)$, $225-242$.

Dollery, B. \& Worthington, A. (1995). Federal Expenditure and Fiscal Illusion: A Test of the Flypaper Hypothesis in Australia. Publius, 25(1), 2334.

Drew, J., Kortt, M. A., \& Dollery, B.E. (2016). Did the Big Stick Work? An Empirical Assessment of Seale Economies and the Queenstand Forced Amalgamation Program. Local Government Studies, 42,(1), 115.

\section{Feiock, R. (2007). Rational Choice and Regional Governance. Journal of Urban Affairs, 29,}

\section{$(1), 47-63$}

Grant, B., \& Drew, J. (2017). Local Government in Australia: History, Theory and Public Policy. Singapore: Springer Palgrave.

Holcombe, R., \& Williams, D. (2008). The Impact of Population Density on Municipat Government Expenditures. Public Finance Review, 36_(3), 359-373.
Formatted: Font: Italic

Formatted: Font: Italic

Formatted: Highlight

Formatted: Font: Italic, Highlight

Formatted: Highlight

Formatted: Font: Italic, Highlight

Formatted: Highlight

Formatted: Font: Italic 
Klok, P., Denters, B., Bodgers, M. \& Sanders, M. (2018). Intermunicipal Cooperation in the Netherlands: The Costs and the Effectiveness of Polycentric Regional Governance, Public Administration Review, https://dei.org/10.1111/puar.12931

KPMG. (2015). Shared Service Analysis: Final report 27 May 2015. Sydney: KPMG.

LeRoux, K., Brandenburger, P., \& Pandey, S. (2010). Interlocal Service Cooperation in U.S.

Cities: A Social Network Explanation. Public Administration Review March April:70,2, $\underline{268-278 .}$

Loeal Government Association of South Australia (LGASA). (2017). SA Local Government Sector Financial Indicators Report 2017. Adelaide: LGASA.

Noda, Y. (2017). Forms and Effects of Shared Services: An Assessment of Loeal

Government Arrangements in Japan. Asia Pacific Joumal of Public Administration, 39,(1), $39-50$.

Oates, W. (2011). Fiscal Federalism. Cheltenham: Edward Elgar.

Tiebout, C. (1956). A Pure Theory of Local Expenditures. Journal of Political Economy, 64,

\section{5), 416-424}

Formatted: Highlight

Formatted: Font: Italic, Highlight

Formatted: Highlight

Formatted: Font: Italic, Highlight

Formatted: Highlight

Formatted: Font: Italic

Formatted: Highlight

Formatted: Font: Italic, Highlight

Formatted: Highlight 